\title{
Links between satellite-retrieved aerosol and precipitation
}

\author{
E. Gryspeerdt ${ }^{1, *}$, P. Stier ${ }^{1}$, and D. G. Partridge ${ }^{1}$ \\ ${ }^{1}$ Department of Physics, University of Oxford, Oxford, UK \\ *now at: Institute for Meteorology, Universität Leipzig, Leipzig, Germany
}

Correspondence to: E. Gryspeerdt (gryspeerdt@atm.ox.ac.uk)

Received: 28 February 2014 - Published in Atmos. Chem. Phys. Discuss.: 13 March 2014

Revised: 18 June 2014 - Accepted: 24 July 2014 - Published: 16 September 2014

Abstract. Many theories have been proposed detailing how aerosols might impact precipitation, predicting both increases and decreases depending on the prevailing meteorological conditions and aerosol type. In convective clouds, increased aerosol concentrations have been speculated to invigorate convective activity. Previous studies have shown large increases in precipitation with increasing aerosol optical depth, concluding an aerosol effect on precipitation. Our analysis reveals that these studies may have been influenced by cloud effects on the retrieved aerosol, as well as by meteorological covariations.

We use a regime-based approach to separate out different cloud regimes, allowing for the study of aerosol-cloud interactions in individual cloud regimes. We account for the influence of cloud properties on the aerosol retrieval and make use of the diurnal sampling of the TRMM satellite and the TRMM merged precipitation product to investigate the precipitation development.

We find that whilst there is little effect on precipitation at the time of the aerosol retrieval, in the $6 \mathrm{~h}$ after the aerosol retrieval, there is an increase in precipitation from cloud in high-aerosol environments, consistent with the invigoration hypothesis. Increases in lightning flash count with increased aerosol are also observed in this period. The invigoration effect appears to be dependent on the cloud-top temperature, with clouds with tops colder than $0^{\circ} \mathrm{C}$ showing increases in precipitation at times after the retrieval, as well as increases in wet scavenging. Warm clouds show little change in precipitation development with increasing aerosol, suggesting ice processes are important for the invigoration of precipitation.

\section{Introduction}

The relationship between precipitation and atmospheric aerosols is complicated, with many competing effects hypothesised depending on the prevailing meteorological conditions and cloud regimes (Levin and Cotton, 2009).

In marine stratocumulus clouds, both theory and observations have suggested that an increased level of cloud condensation nuclei $(\mathrm{CCN})$ can cause a reduction in cloud droplet size and increase the albedo of the cloud (for a fixed liquid water content). This is known as the "cloud albedo effect" (Twomey, 1977). This change in the droplet size distribution has been hypothesised to result in the suppression of precipitation, which may lead to an increase in the liquid water path of these clouds (Albrecht, 1989). Both of these effects are generated by a change in cloud droplet number concentration and size and thus cannot be considered separately, as feedbacks from one can influence the strength of the other.

Mixed-phase clouds are comparatively more complicated than liquid clouds, with the ice phase adding a new dimension to the interaction of aerosols with precipitation. Theoretical arguments have been made for an aerosol invigoration of precipitation in mixed-phase clouds. Williams et al. (2002) and Rosenfeld et al. (2008) describe a mechanism where the suppression of precipitation in the early stages of cloud development in a high-CCN environment may lead to an increased probability of a cloud developing above the freezing level, where the increased buoyancy supplied by the droplet freezing might then lead to an invigoration of precipitation. Precipitation invigoration is also considered by Stevens and Feingold (2009), although they note that in a buffered system (that is, one where many competing pathways may act to change the output), detecting the response to a perturbation can be difficult. 
Observational studies of precipitation from convective clouds show varying links between aerosol and precipitation properties, with some showing an positive and some a negative correlation between precipitation and satellite-retrieved aerosol. Several observational studies have shown a decrease in precipitation in high-aerosol environments (Rosenfeld, 1999; Huang et al., 2009; Sorooshian et al., 2009), whilst others suggest an increase in precipitation in both satellite (Lin et al., 2006; Koren et al., 2012; Niu and Li, 2012) and ground-based remote sensing measurements (Li et al., 2011). At very high aerosol concentrations with significant absorption, other effects have been noted. Koren et al. (2008) show that although aerosols may act to increase cloud formation at low aerosol optical depth (AOD), the radiative effect of aerosols may dominate microphysical effects at high AOD, suppressing cloud formation.

Modelling studies of mixed-phase clouds also show varying results. Lebo and Seinfeld (2011) show a decrease in precipitation from mixed-phase clouds in high-CCN environments. In their model, they find that even an increase in ice nuclei (IN) may not produce a statistically significant increase in precipitation. Khain (2009) notes a variety of different effects of aerosol on precipitation in models, depending on the cloud regime and environmental conditions.

A link has been shown between satellite-retrieved AOD and precipitation globally (Koren et al., 2012), with an almost universal increase in precipitation with increasing AOD being found, similar to that in Fig. 1. Whilst the interpretation of this result has been disputed (Boucher and Quaas, 2012; Koren et al., 2013), it shows a strong link between satelliteretrieved aerosol and precipitation properties. The cause of this relationship is less clear, and may be due to meteorological covariation, satellite-retrieval errors or aerosol influences on precipitation.

When considering precipitation and aerosol, wet scavenging is also important, as precipitation is expected to remove aerosol from the atmosphere and is the dominant removal mechanism for many aerosol species (Textor et al., 2006). A negative relationship between AOD and precipitation might be indicative of this relationship. It is also possible that this negative relationship cannot be observed using satellites, as they cannot sample the aerosol in cloud-covered scenes where the wet scavenging is occurring (Grandey et al., 2013).

It is important to note that a change in precipitation is fundamentally limited by the planetary energy balance (e.g. Allen and Ingram, 2002). The processes investigated in this work might change the local precipitation, but we assume that any change is balanced by non-local effects such that there is no change in the global mean precipitation.

Several interactions could be causing the observed relationships. Both precipitation and aerosol optical depth are notoriously hard to retrieve using space-based instruments. Aerosol retrievals are used as a proxy to $\mathrm{CCN}$, and while both AOD (Andreae, 2009) and aerosol index (AI - AOD multiplied by Ångström exponent) (Nakajima et al., 2001) are

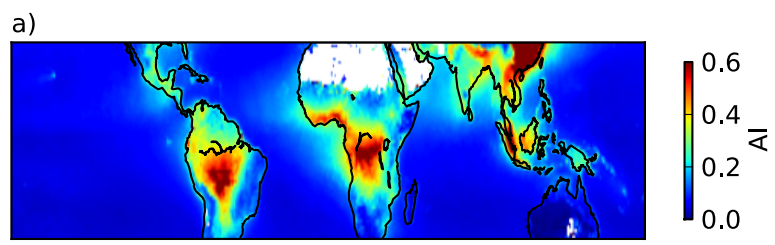

b)

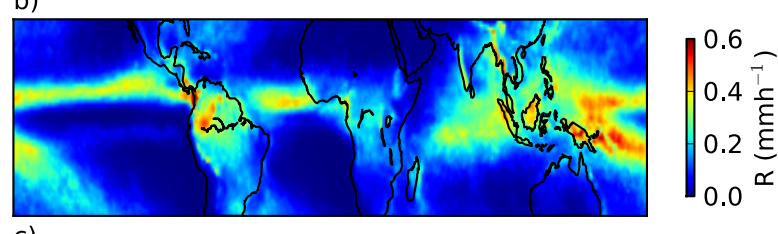

c)

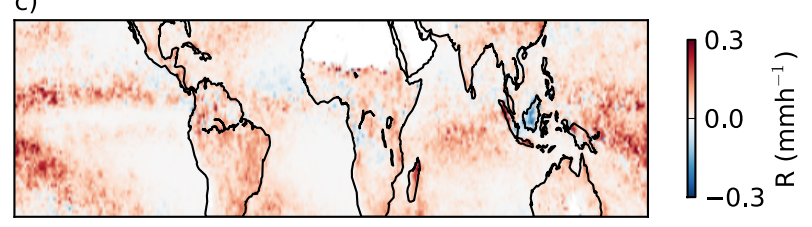

Figure 1. (a) The annual mean MODIS aerosol index (AI) in the region studied $\left(30^{\circ} \mathrm{N}-30^{\circ} \mathrm{S}\right)$ for the years 2005-2007. (b) The annual mean TRMM 3B42 merged precipitation rate in the same region. (c) The difference in TRMM 3B42 precipitation rate between days in the highest AI quartile and days in the lowest AI quartile, with red indicating an increase in precipitation at high AI (based on Koren et al., 2012)

generally indicative of $\mathrm{CCN}$ abundance, they are also susceptible to humid swelling (Twohy et al., 2009) and cloud contamination of the retrieval (Kaufman et al., 2005; Zhang et al., 2005), as well as 3-D effects (Wen et al., 2007), where light scattered from the side of clouds can artificially increase the retrieved AOD. These interactions modify the retrieved AOD without changing the CCN, and their strength is related to the cloud properties. These interactions are hypothesised to cause a large part of the AOD-cloud-fraction (CF) relationship (Quaas et al., 2010; Grandey et al., 2013) and have been referred to as type-one meteorological errors (Gryspeerdt et al., 2014b). A perfect CCN retrieval would remove type-one meteorological covariations. Some meteorological properties modify both the retrieved AOD and the underlying CCN, such as dust outflow from the Sahara often being accompanied by warm dry air. These are referred to as type-two meteorological covariations and would exist even with a perfect CCN retrieval (Gryspeerdt et al., 2014b).

In this work, we make use of the methods of Gryspeerdt and Stier (2012) and Gryspeerdt et al. (2014b) to reduce the influence of meteorological and retrieval issues on the relationship between precipitation and retrieved aerosol. We use multiple precipitation retrievals to investigate the precipitation development of separate cloud regimes, accounting for the influence of cloud fraction and meteorological effects at the time of the aerosol retrieval. This enables us to gain a clearer picture of how aerosols might be influencing precipitation properties. 


\section{Methods}

Both the aerosol effects on precipitation and meteorological influences on the correlation between aerosol and precipitation are expected to be strongly influenced by the cloud type, with aerosol invigoration effects expected primarily in convective regimes. Meteorological covariations, where aerosol and cloud properties are correlated because they are linked to a meteorological parameter (such as relative humidity; Quaas et al., 2010; Grandey et al., 2013), are particularly pervasive when considering relationships between aerosol and cloud properties, due to the strong influence of meteorological properties on cloud and aerosol properties separately. To attempt to reduce these influences, we separate our retrievals by cloud regime, in the manner of Gryspeerdt and Stier (2012) and Williams and Webb (2009). This method assigns clouds to regimes based on the mean cloud fraction, cloud-top pressure and cloud optical depth, with the regime properties being determined using a k-means clustering method. The centroids necessary to recreate the regimes for the region used in this study are listed in Table 1. We use the region $30^{\circ} \mathrm{N}-30^{\circ} \mathrm{S}, 180^{\circ} \mathrm{W}-180^{\circ} \mathrm{E}$ over the period 2003-2007 in this study (2003-2009 for the maps of precipitation change).

We use MODIS for both aerosol (Remer et al., 2005) and cloud (Platnick et al., 2003) properties. These are both from the collection 5.1 level 3 daily data, at $1^{\circ}$ by $1^{\circ}$ resolution. We use the AI as our aerosol product, as it includes a size dependence and has been shown to correlate better with CCN (Nakajima et al., 2001). High and low aerosol are defined as the highest and lowest AI quartiles respectively, and are defined separately for each $1^{\circ}$ by $1^{\circ}$ location, regime and season. The varying definitions mean that the difference between high and low aerosol varies by location, regime and season, with a large difference between high and low $\mathrm{AI}$ in regions with a large AI variation, such as the Bay of Bengal. The mean AI value is strongly influenced by the high values due to the AI distribution being biased towards smaller values. This means that high-AI regions typically have a large variation in AI. As precipitation is typically heavier in high cloud fraction regimes, to prevent sampling issues, we use the spatial interpolation method of Koren et al. (2012). This method interpolates aerosol retrievals into cloud-covered pixels that are adjacent to pixels with a valid AI retrieval.

The strength of the AI-CF relationship may affect many different correlations between aerosol and cloud properties. Gryspeerdt et al. (2014b) showed that both mid-level and deep convective clouds are correlated with higher MODIS $\mathrm{AI}$, and that although this might appear to indicate an invigoration effect, it is probably a result of the strong correlation between $\mathrm{AI}$ and CF due to effects other than an aerosol influence on clouds. To account for this, we follow the method of Gryspeerdt et al. (2014b), which ensures that, at the time of the aerosol retrieval, the distributions of $\mathrm{CF}$ within each regime are the same for both the high and low AI populations. This helps to reduce the influence of cloud fraction on aerosol, as well as reduce the effect of meteorological factors which cause the AI-CF relationship. Using this method reduces the difference in mean $\mathrm{CF}$ between the high and low aerosol populations to less than $1 \%$, which removes the AI$\mathrm{CF}$ link at the time of the aerosol retrieval. This process is also repeated for ECMWF ERA-Interim $850 \mathrm{hPa}$ relative humidity $(\mathrm{RH})$ and $500 \mathrm{hPa}$ pressure vertical velocity $\left(\omega_{500}\right)$.

As noted in Gryspeerdt et al. (2014b) and the supplementary information of Koren et al. (2012), removing the link between CF and AI will reduce the vertical extent of the sample of clouds under investigation. This in turn can remove any links between $\mathrm{AI}$ and precipitation, including links due to an aerosol effect on precipitation. To avoid this, we make use of the diurnal nature of the cloud and precipitation cycle in the tropics.

By using multiple different satellite retrievals, both before and after the AI retrieval, we can determine how aerosol is related to the development of precipitation. This allows us to account for the AOD-CF relationship, unlike studies that use "snapshots" of satellite-retrieved properties.

For precipitation retrievals, we use the TRMM merged precipitation product (3B42) (Adler et al., 2000; Huffman et al., 2007). In this work, we use version 7 of the $3 B 42$ product regridded to a $1^{\circ}$ by $1^{\circ}$ resolution. For each TRMM 3B42 precipitation retrieval, the closest MODIS aerosol and cloud regime retrievals are determined, noting the time offset between the MODIS and the precipitation retrievals. These time offsets from the MODIS retrievals are then used to calculate the diurnal cycle of precipitation for each regime. Due to possible missing data and sparse retrievals, we do not attempt to track the development of individual clouds; rather, we only infer the development of the regimes. The TRMM merged precipitation product is based primarily on the TRMM 13.8 GHz radar and passive microwave precipitation retrievals. This limits the direct detection of light precipitation, as it is below the detection threshold of the TRMM radar (Kummerow et al., 1998). The reduction in detection ability means that we are unlikely to be able to observe any suppression of warm precipitation from shallow clouds.

At $1^{\circ}$ by $1^{\circ}$ resolution, advection can cause a significant change in the properties of a single $1^{\circ}$ by $1^{\circ}$ grid box over a period of $12 \mathrm{~h}$. To account for this, we make use of the HYSPLIT Lagrangian trajectory model (Draxler and Hess, 1998), using NCEP reanalysis to run the model. The starting altitude is determined separately for each regime (Table 1 ), and the model is run forward and backward $12 \mathrm{~h}$ across the study region to account for the effect of advection on the observed results. We determine the starting altitude based on the cloud regime. It is possible that the aerosols are located at a different height to the clouds and thus do not follow the HYSPLIT trajectory determined for the clouds. This should have a minimal impact due to the larger spatial scales of aerosols compared to clouds (Weigum et al., 2012) and the 
Table 1. Cloud regimes used in this study, from Gryspeerdt and Stier (2012). The mean GPCP rain rate (Huffman et al., 2009) and the initial height used for the HYSPLIT trajectory analysis are also included.

\begin{tabular}{lccccc}
\hline Regime & Albedo $(\%)$ & CTP $(\mathrm{hPa})$ & $\mathrm{CF}(\%)$ & Rain $\left(\mathrm{mm} \mathrm{d}^{-1}\right)$ & HYSPLIT altitude $(\mathrm{m})$ \\
\hline Shallow cumulus & 45.2 & 551 & 24.7 & 1.13 & 1000 \\
Thick mid-level & 62.8 & 261 & 97.6 & 10.56 & 3000 \\
Thin mid-level & 40.0 & 270 & 84.3 & 5.54 & 6000 \\
Transition & 40.5 & 856 & 58.3 & 0.99 & 1000 \\
Anvil cirrus & 33.7 & 137 & 88.0 & 6.54 & 8000 \\
Deep convective & 69.7 & 127 & 98.6 & 23.68 & 6000 \\
Stratocumulus & 48.7 & 745 & 83.9 & 1.75 & 1000 \\
\hline
\end{tabular}

Table 2. The mean total TRMM 3B42 merged precipitation $(\mathrm{mm})$ for the $6 \mathrm{~h}$ following $T+0$ for the years 2003-2007. These are the mean precipitation rates over the period $T+0 \rightarrow+6$ for each of the sub-figures in Fig. 2.

\begin{tabular}{lcccc}
\hline Regime & $\begin{array}{c}\text { Ocean }\left(\mathrm{mm} \mathrm{day}^{-1}\right) \\
\text { High AI }\end{array}$ & Low AI & $\begin{array}{c}\text { Land }\left(\mathrm{mm} \mathrm{day}^{-1}\right) \\
\text { High AI }\end{array}$ & Low AI \\
\hline Total & 2.10 & 0.78 & 6.13 & 4.11 \\
\hline Shallow cumulus & 0.58 & 0.47 & 2.98 & 2.20 \\
Thick mid-level & 10.4 & 9.19 & 13.8 & 11.7 \\
Thin mid-level & 2.10 & 1.87 & 5.85 & 4.22 \\
Transition & 0.72 & 0.56 & 4.11 & 2.73 \\
Anvil cirrus & 1.63 & 1.54 & 4.09 & 3.01 \\
Deep convective & 28.9 & 26.7 & 33.8 & 29.5 \\
Stratocumulus & 1.63 & 1.44 & 6.38 & 4.75 \\
\hline
\end{tabular}

short timescales involved. Any errors in the HYSPLIT trajectories should be random rather than a systematic function of aerosol (Engström and Magnusson, 2009), so by using several years of data, we reduce the impact of errors in the trajectories.

In addition to these main data sets, we also make use of several other data sets in a lesser capacity. The TRMM Lightning Imaging Sensor (LIS) also provides a measure of the activity of convective systems (Christian, 2003). By using highfrequency optical measurements, the LIS is able to determine the lightning flash rate of storms in a $90 \mathrm{~s}$ observation period. An increase in lightning flash rate indicates increased vigour in a convective system. Increases in flash rate with increased AOD have been previously observed in the western Pacific (Yuan et al., 2011).

Finally, we make use of the ISCCP 3-hourly D1 data set (Rossow and Schiffer, 1999). We use this to provide cloudtop temperatures at several times during the day to investigate the effects of cloud-top temperature on the precipitation development, and on the possible aerosol-precipitation interactions. The ISCCP and TRMM LIS data are regridded to a $1^{\circ}$ by $1^{\circ}$ resolution.

Using the diurnal sampling ability of TRMM merged product, we are able to examine how precipitation development varies for different regimes and aerosol environments. This can account for the influence of CF and other meteoro- logical properties at the time of the retrieval, whilst still allowing cloud vertical development, and time for any aerosol effects to act on the cloud properties.

\section{Results}

\subsection{Temporal variations}

We use Aqua MODIS to provide the AI and cloud retrievals, defining time zero $(T+0)$ as the satellite overpass time (13:30 local solar time, LST). Without separating our data by regime, we find a differing diurnal cycle over both land and ocean (Fig. 2a, b). Over land (Fig. 2b), the peak precipitation rate occurs at approximately $T+4(17: 30 \mathrm{LST})$, with a minimum in precipitation around $T-2(11: 30 \mathrm{LST})$. Over ocean (Fig. 2a), the peak in precipitation is less clearly defined, occurring between around $T-12$ and $T-6(01: 30$ and 07:30 LST). We also see the mean precipitation rate over land is higher than that over ocean, although the daily minimum rain rate is similar, at about $0.05 \mathrm{~mm} \mathrm{~h}^{-1}$.

To separate our data by regimes, we use the regime defined at $T+0$. For example, this means that the deep convective regime (Fig. $2 \mathrm{~m}, \mathrm{n}$ ) is only guaranteed to be a deep convective cloud at $T+0$. The cloud regimes transition to other regimes over the observation period (the influence of aerosols 

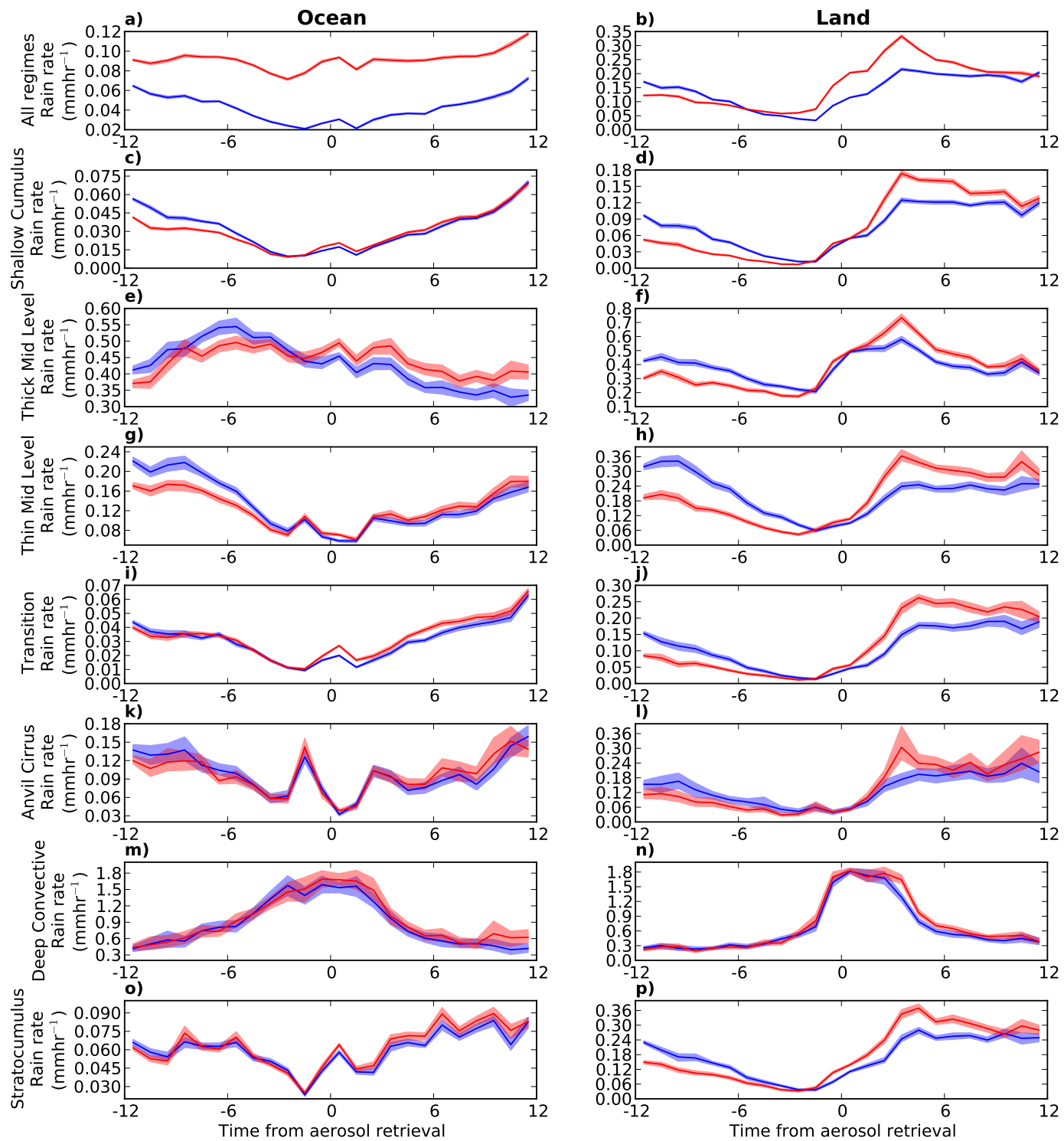

Figure 2. Mean precipitation rain rates at times before and after the Aqua MODIS aerosol and cloud retrieval at $T+0$ (13:30 LST) for the region $30^{\circ} \mathrm{N}-30^{\circ} \mathrm{S}$. The development in a high-AI environment is shown in red and a low AI environment in blue. Statistical errors are shown at $95 \%$ significance. The top row ("All regimes") shows the development of precipitation if cloud regimes and the AI-CF relationship are not accounted for. These plots are created from MODIS L3 cloud and aerosol data and TRMM 3B42 $3 \mathrm{~h}$ merged precipitation data over the five years 2003-2007. Numerical values for the mean precipitation within $T+0 \rightarrow+6$ are given in Table 2

on the transition frequencies is investigated in Gryspeerdt et al., 2014b). The transitioning between regimes means that it is very unlikely that the clouds in the deep convective regime at $T+12$ are still deep convective clouds. However, they have all transitioned from the deep convective regime at $T+0$, and thus the life cycle of the regimes can be studied.

As the regime is only guaranteed at $T+0$, apparent diurnal cycles can be generated in regimes/locations where the real diurnal cycle is weak or where the frequency of occurrence of a regime is particularly low. For example, deep convective clouds found over ocean at 13:30 LST are not part of a strong diurnal cycle (Fig. $2 \mathrm{~m}$ ). The weak diurnal cycle means that we are as likely to find them early as we are to find them late in their life cycle. As the deep convective regime has the heaviest precipitation (Table 1), this generates a peak in the precipitation rate at $T+0$ and a reduction in precipitation rate before and after $T+0$ that is defined by the timescale for formation/decay of the deep convective regime. This effect is most significant for deep convective clouds over ocean, but also affects deep convective clouds over land when $T+0$ is 10:30 LST (Fig. 3n). 

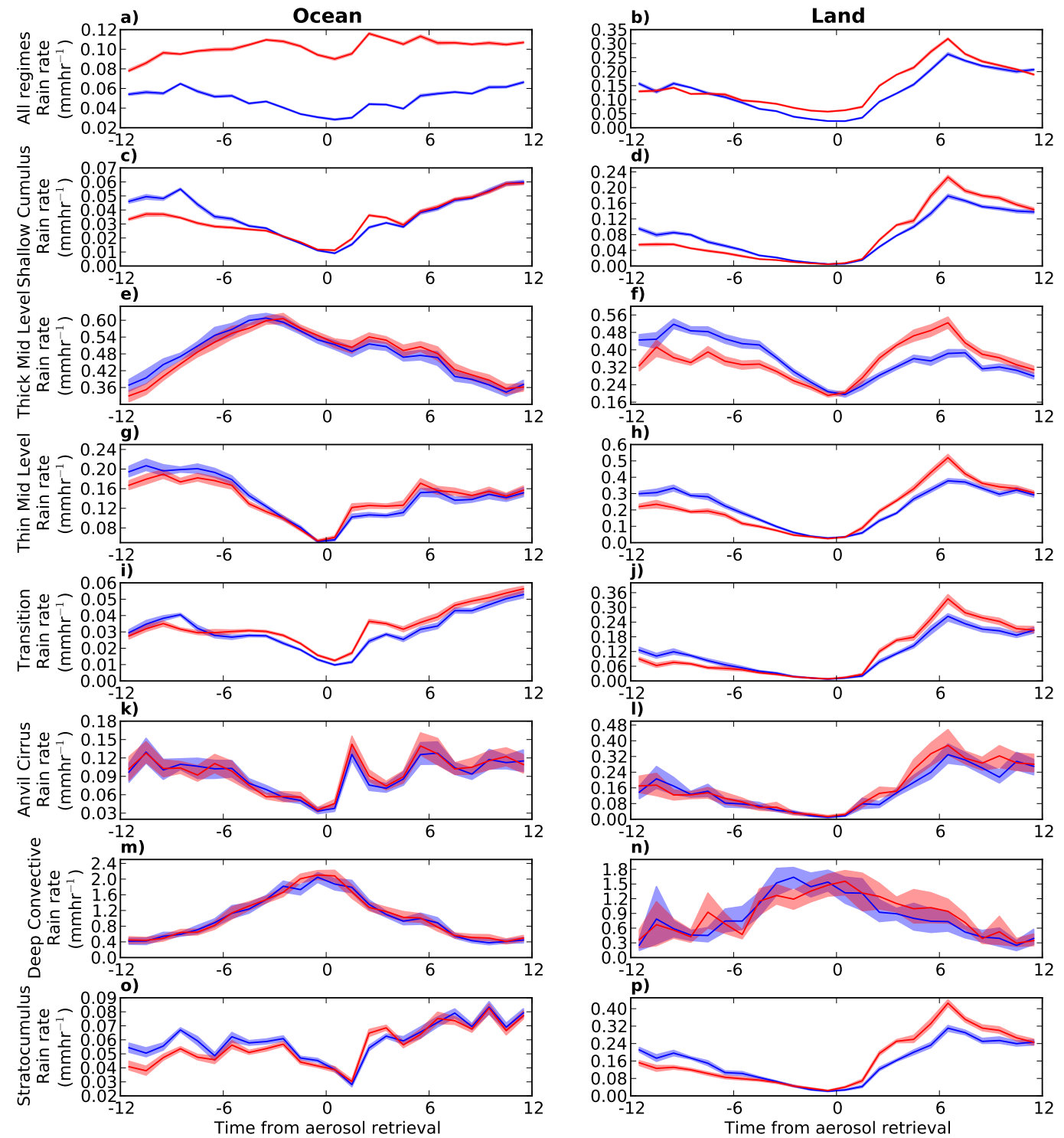

Figure 3. As Fig. 2, but using Terra MODIS for the cloud and aerosol retrievals, giving a $T+0$ of 10:30 LST.

The difference in precipitation rate between the high and low AI populations when not considering regimes or meteorological state is large (Fig. 2a, b), especially over ocean (Fig. 2a), where there is a strong increase in precipitation with AI. At $T+0$, the difference in precipitation rates is comparable to those found by Koren et al. (2012), although there are some differences in how our data are prepared (we use quartiles rather than terciles for determining high and low AI). Without limiting the study to specific cloud regimes or accounting for the AI-CF correlation, the high AI population has a precipitation rate almost 3 times the low AI population at $T+0$ over ocean, and over land the increase is approximately $50 \%$ (Table 2).

Separating our data into cloud regimes and accounting for $\mathrm{CF}$ at the time of the AI retrieval reduce the link between $\mathrm{AI}$ and precipitation at $T+0$ (Fig. 2c-p). Over ocean the difference in precipitation between the high and low AI populations is eliminated completely in almost all of the regimes, with only the transition and shallow cumulus regimes showing a small difference. Over land, only the stratocumulus regime shows a significant difference in precipitation rate between the high and low AI populations at $T+0$, although the difference is small (Fig. 2p). The minimal difference in $T+0$ precipitation rate between the high and low AI populations is important, as we have not explicitly reduced it; we only minimise the difference in $\mathrm{CF}, \mathrm{RH}$ and $\omega_{500}$. This emphasises the strength of the correlation between $\mathrm{CF}$ and precipitation rate, suggesting that $\mathrm{CF}$ may act to mediate the AI-precipitation correlation in the same way as the AOD-cloud-top-pressure (CTP) correlation (Gryspeerdt et al., 2014a). 

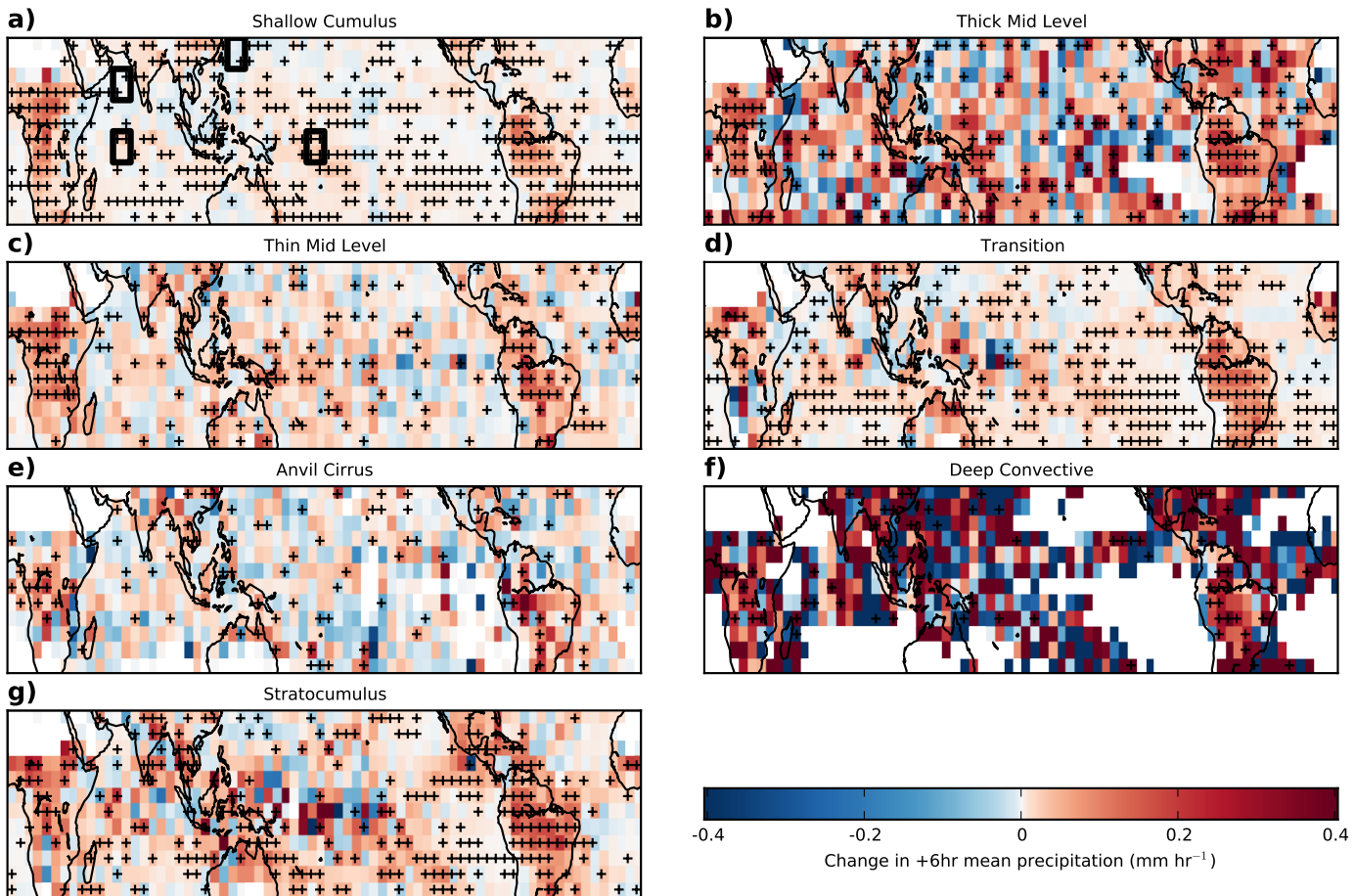

Figure 4. The difference in mean precipitation between the high and low AI populations from $T+0$ to $T+6$ using Aqua MODIS ( $T+0$ at 13:30 LST) for each regime, averaged over $5^{\circ}$ by $5^{\circ}$ regions for the period 2003-2009. Red indicates an increase in precipitation at high AI. Crosses indicate $95 \%$ statistical significance. The boxes on the shallow cumulus plot are the regions selected for further study (see Supplement).
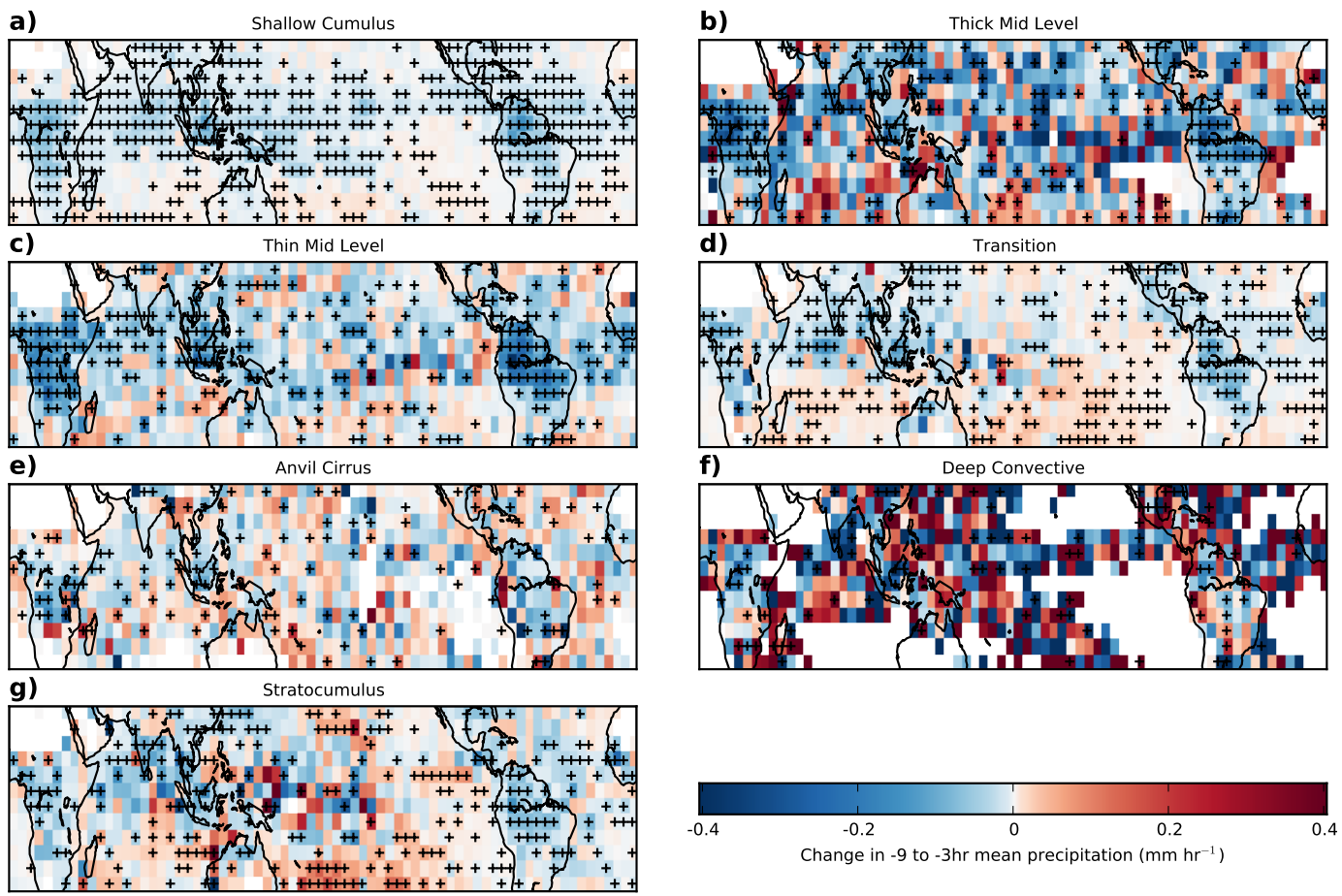

Figure 5. Mean precipitation difference between the high and low AI populations from $T-9$ to $T-3$ ( $T+0$ at 13:30 LST) over the period 2003-2009. Red indicates an increase in precipitation at high AI. Crosses indicate $95 \%$ statistical significance. 


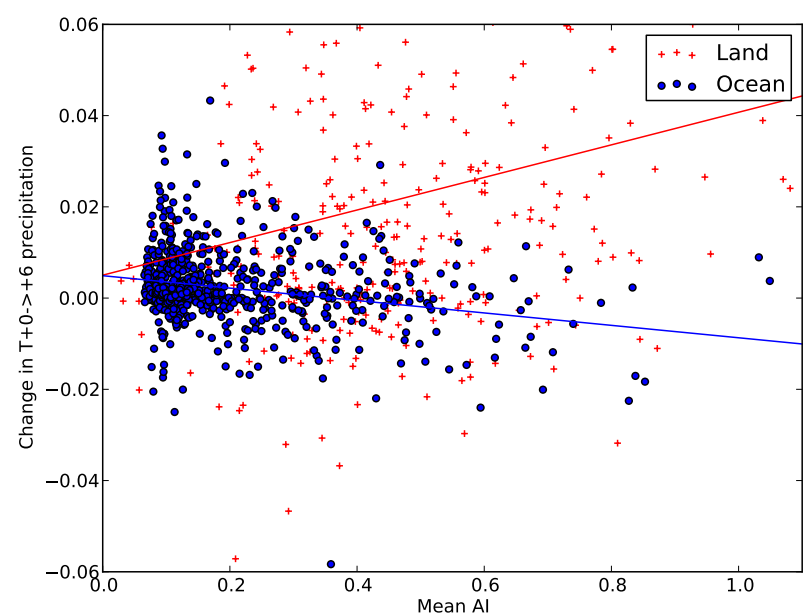

Figure 6. The dependence of the mean precipitation rate over the period $T+0 \rightarrow+6$ on local mean AI for oceanic (blue dots) and continental (red crosses) shallow cumulus. The change in precipitation points are taken from Fig. 4a. The straight lines are linear regressions over land (red) and ocean (blue) respectively.

Over ocean, the regimes show similar precipitation development in both the high and low AI populations. The deep convective regime shows little difference in mean precipitation rate between the high and low AI populations, and the thick mid-level regime (Fig. 2e) shows only a small increase in precipitation in the high AI population compared to the low AI population. The stratiform regimes show slight increases in precipitation at times after the AI retrieval (Fig. 2c, $\mathrm{i}, \mathrm{o})$. They also show small differences in precipitation rate at $T+0$, although these are much smaller than those found when not accounting for the influence of the strong AI-CF correlation (Fig. 2a). Over land (Fig. 2d, f, h, j, 1, n, p), the differences in precipitation development are much more striking, with all the regimes showing increased precipitation for the high AI population after $T+0$ compared to the low AI population. It should be noted that although the statistical errors are shown in Fig. 2, the variation in the precipitation rate through the day indicates larger errors in some of the regimes, especially those with low precipitation rates and a low frequency of occurrence (RFO), such as marine stratocumulus.

Many of the regimes show a higher rain rate from the low AI population than the high AI population before $T+0$, over both land and ocean. When the data are not separated by regime, this difference in pre- $T+0$ precipitation is seen over land, but to a lesser extent (Fig. 2b). A higher precipitation rate at times before $T+0$ is associated with a lower retrieved $\mathrm{AI}$ at $T+0$ through wet scavenging, which removes aerosol from the atmosphere. This generates an inverse relationship between pre- $T+0$ precipitation and retrieved AI at $T+0$.

The time of maximum precipitation and maximum difference in rain rate between the high and low AI populations differs by regime. The deep convective regime (Fig. 2n) ex- periences a maximum in precipitation rate between $T+0$ and $T+2$, whilst the thick mid-level regime shows a maximum at around $T+3 / T+4$ and a significant increase in precipitation at $T+0$ (Fig. 2f). The stratiform regimes exhibit a maximum even later, at around $T+4 / T+5$ (Fig. $2 \mathrm{j}$, p). This change in the time of peak precipitation is due to the development of the regimes and transitions between them. Some of the thick mid-level clouds will transition into the deep convective regime in the hours after $T+0$, where they will have higher rain rates. The thick mid-level regime can be considered as partially developed deep convective clouds, which only reach their peak rain rate once they have transitioned into the deep convective regime, exhibiting a later precipitation peak. This development is evident in the shallow cumulus regime (Fig. 2d), where the peak precipitation rate lasts for a longer period of time and is later in the day, when some of the shallow cumulus clouds have transitioned to the thick mid-level or deep convective regimes. As this could be expected to take longer than the transition from thick mid-level to deep convective, the time of peak precipitation is later. This provides a good example of how the regime-based analysis separates out clouds with different properties and at different stages of development.

Due to the timing of the diurnal cycle, many of the convective regimes observed using a $T+0$ of 13:30 LST will have already started to develop. We gain extra information by using Terra MODIS with a $T+0$ of 10:30 LST to further investigate the precipitation development of these regimes (Fig. 3).

The overall patterns are very similar when using Terra AI and a $T+0$ of 10:30 LST (Fig. 3) compared to Aqua AI and a $T+0$ of 13:30 LST (Fig. 2). The deep convective regime over land now shows similar features to the deep convective regime over ocean, with a peak at $T+0$ and a steady buildup/decay in rain rate before and after $T+0$. This is due to the lack of deep convective clouds at this stage in the diurnal cycle over land.

The most notable difference is in the thick mid-level regime over land (Fig. 3f), where a much larger fractional increase in precipitation after $T+0$ is observed in the high AI population compared to the low AI population than we see when using Aqua MODIS ( $T+0$ at 13:30 LST). There is an almost $30 \%$ increase in the rain rate of the high AI population over the $6 \mathrm{~h}$ of $T+0 \rightarrow+6$ compared to the low AI population, but no difference in rain rate at $T+0$. The increased sensitivity of the precipitation to AI changes when using Terra MODIS compared to Aqua is due to the diurnal cycle. Many of the deep convective regime clouds that we find when using Aqua MODIS are developing at 10:30 LST, so we find them in the thick mid-level regime. The high AI population thick mid-level clouds are more likely to transition to the deep convective regime over the next $3 \mathrm{~h}$ than the low AI population (Gryspeerdt et al., 2014b). This suggests that, for observing convective systems, 10:30 LST has advantages for use as $T+0$, as it catches the systems as they are developing, rather than when they are already in the deep 

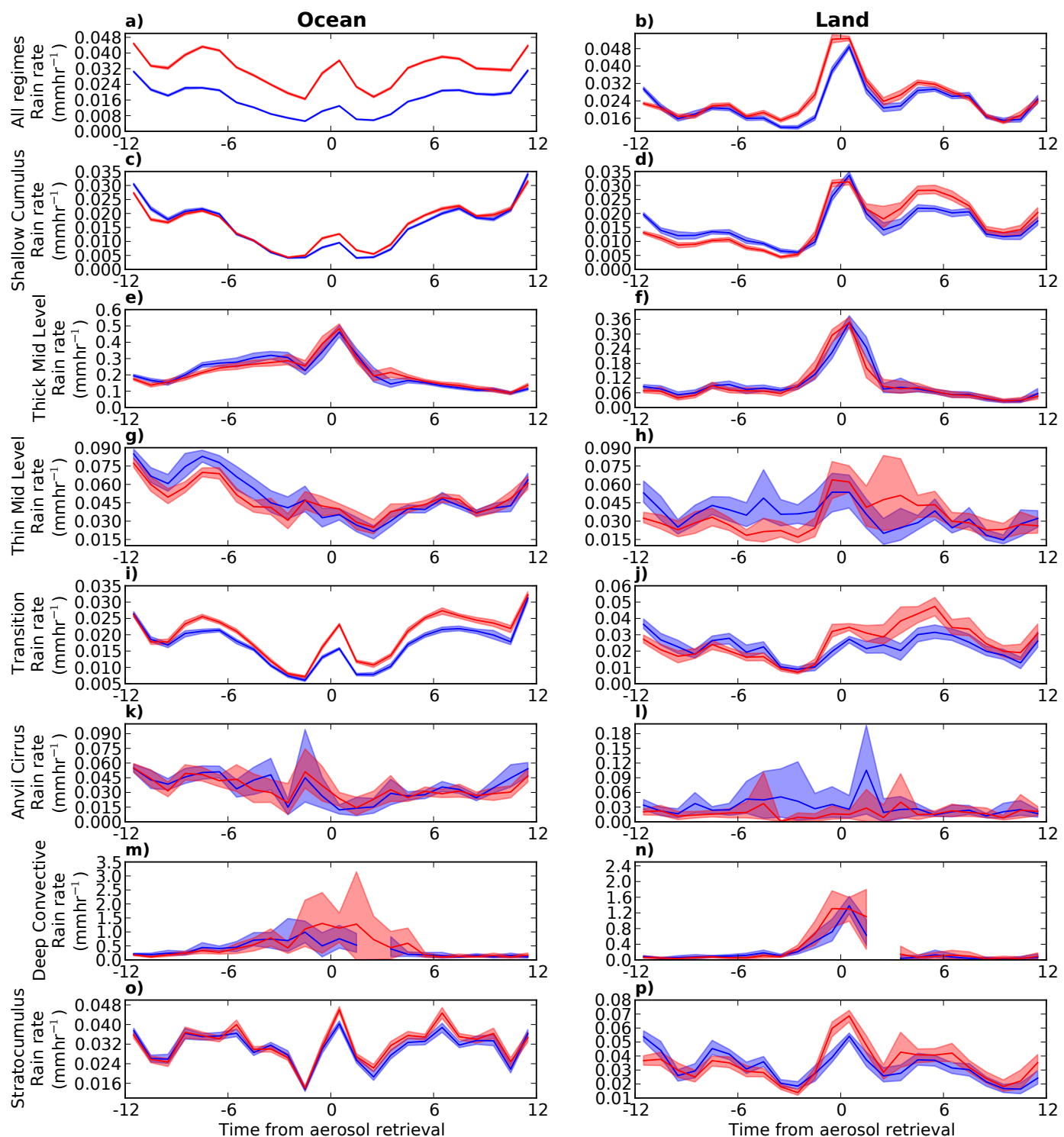

Figure 7. As Fig. 2, but using ISCCP cloud-top temperature (CTT) to remove all clouds with a mean CTT of less then $273 \mathrm{~K}$, keeping only liquid-phase clouds. The gaps in the precipitation development of the deep convective regime (m, $\mathbf{n})$ indicate a lack of data.

convective regime. However, it does not allow for the investigation of developed deep convective regimes due to a low deep convective regime RFO at 10:30 LST.

These regime-based results show similarities to the results found without using regimes, but they also illustrate the importance of accounting for regimes and the AI-CF correlation. Whilst the restriction of CF reduces the vertical extent of the clouds (due to the strong CF-CTP relationship), not accounting for this effect can result in an overestimation of the influence of aerosols on CF by at least a factor of 2 (Gryspeerdt et al., 2014b). Investigating the development of the regimes reduces the effect of $\mathrm{CF}$ on the AI retrieval, whilst allowing an aerosol influence on cloud vertical development.

\subsection{Regional variations}

As most of the precipitation increase with AI occurs in the $6 \mathrm{~h}$ following the aerosol retrieval, we examine the mean rain rate across the period $T+0 \rightarrow+6$ to investigate regional variations in precipitation development. Due to the sparse nature of the data in some regimes, we average over $5^{\circ}$ by $5^{\circ}$ regions (Fig. 4). For the rest of this work, we use only Aqua MODIS to provide the cloud and aerosol properties, giving a $T+0$ of 13:30 LST. This enables us to study both developing and developed deep convective clouds over land, which is not possible when using Terra MODIS. The difference in the regime behaviour is clear, and there are also clear regional variations over the $6 \mathrm{~h}$ window (Fig. 4). The shallow cumulus 

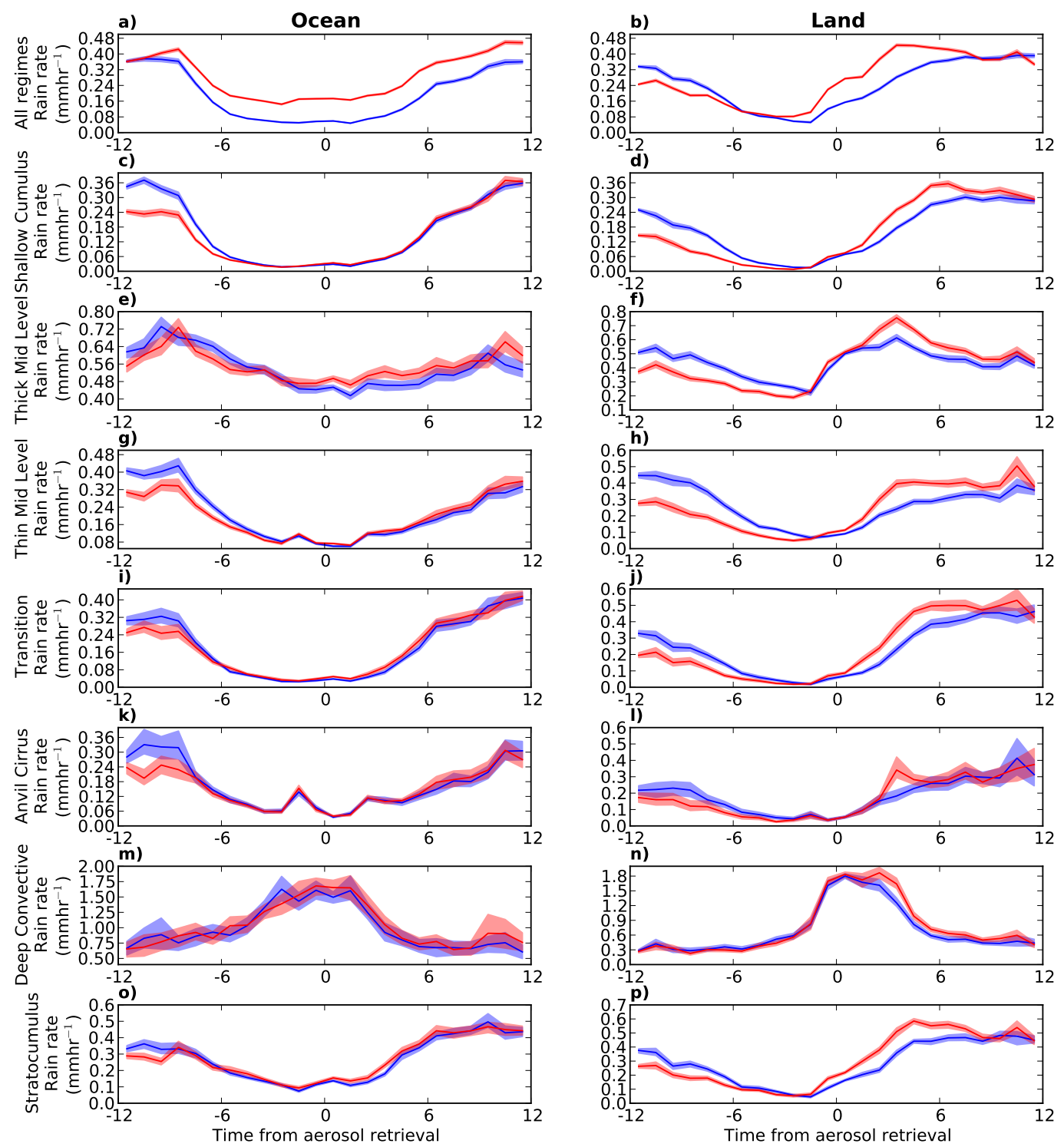

Figure 8. As Fig. 2, but using ISCCP CTT to remove all clouds with a mean CTT of more than $273 \mathrm{~K}$, keeping only mixed- and ice-phase clouds.

regime shows an increase in $T+0 \rightarrow+6$ precipitation (mean precipitation rate between $T+0$ and $T+6$ ) for the high AI population over almost all the continental regions (Fig. 4a). Also notable is the small decrease in mean precipitation over the Arabian Sea and South China Sea for the high AI population. This decrease in precipitation is confined to the region close to land in the Indian Ocean and western Pacific, with increases in precipitation being observed in the eastern $\mathrm{Pa}$ cific and southern Indian Ocean. There are some anomalous decreases in precipitation with increasing AI in the middle of the Pacific Ocean, which is most obvious in the shallow cumulus regime. These are due to an uncertainty in the Aqua overpass time around the international dateline when using level 3 MODIS data.
There are less data from the convective regimes, making determination of any regional patterns difficult (Fig. 4b, f). However, both the thick mid-level (Fig. 4b) and deep convective regimes (Fig. 4f) show some significant increases in mean precipitation over land. Over ocean the results are too noisy to determine the magnitude or sign of any regional effect.

Repeating this analysis over the period $T-9 \rightarrow-3$ (Fig. 5), we see the expected wet scavenging relationship, with higher mean precipitation rates in the low AI population. Although many regions show that the high AI population experienced stronger precipitation over the period $T-9 \rightarrow-3$, some regions (typically in locations with a low mean AI) show the opposite effect. This may indicate 

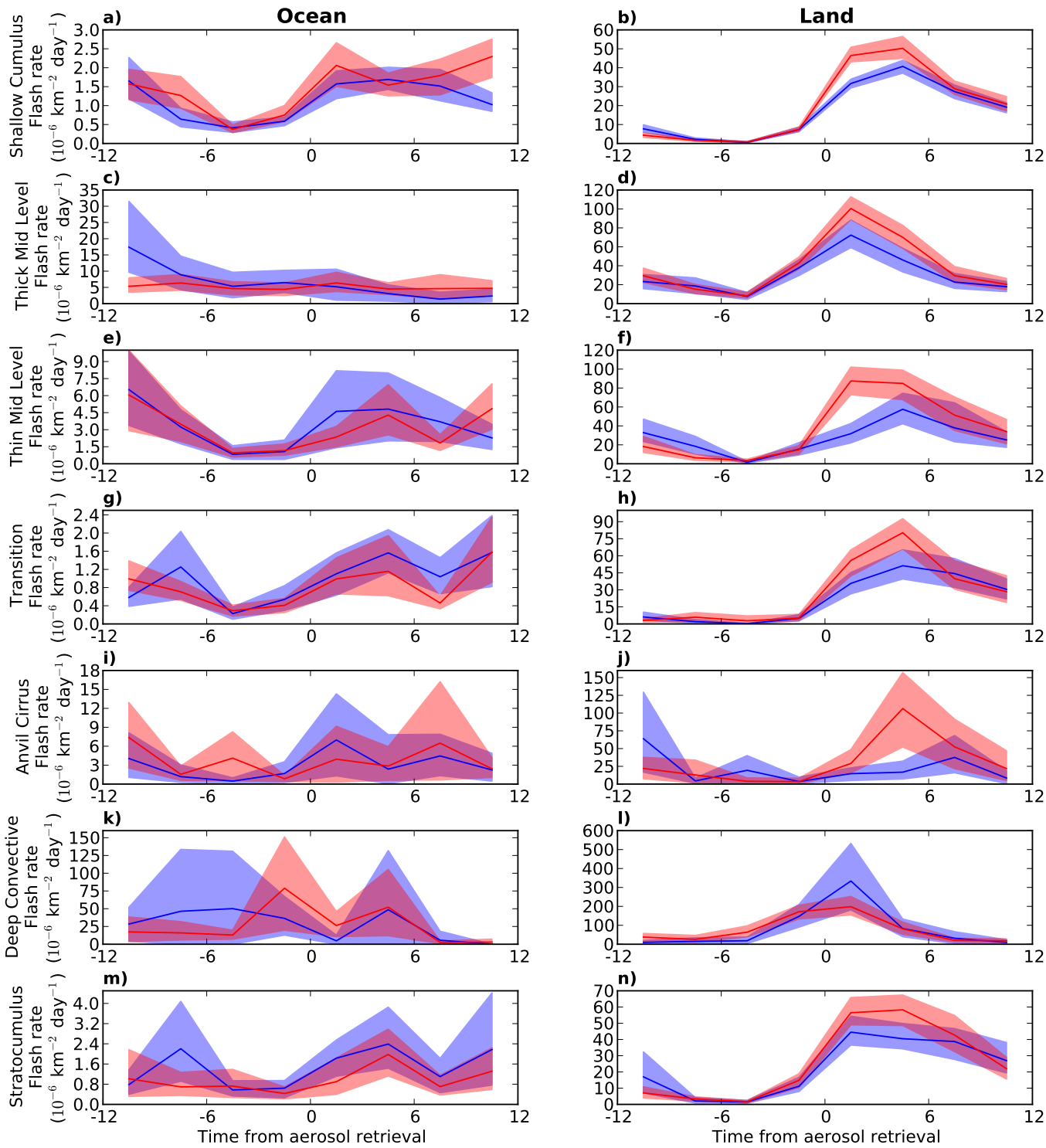

Figure 9. The difference in TRMM LIS flash rate for the high and low AI populations for the study region $\left(30^{\circ} \mathrm{N}-30^{\circ} \mathrm{S}, 180^{\circ} \mathrm{W}-180^{\circ} \mathrm{E}\right)$ over the period 2003-2007. Red indicates the flash rate development for the AI population and blue the low AI population.

that wet scavenging of aerosol is less effective or that a different process, such as an increase in liquid water path in high-aerosol environments, is important in these clean, lowprecipitation-rate regions.

The difference in mean shallow cumulus precipitation rate over the period $T+0 \rightarrow+6$ between the high and low AI populations shows regional differences (Fig. 4a). In general, precipitation increases with increased AI are observed over the ocean. However, in the northern Indian Ocean and the East China Sea, decreases in precipitation with increasing AI are observed over the $T+0 \rightarrow+6$ period (Fig. 1a).

Over ocean, the difference in precipitation between the high and low AI populations over the $T+0 \rightarrow+6$ period is negatively correlated to the mean AI (Fig. 6, $r=-0.25$ ).
This negative correlation indicates that different processes become important as aerosol concentrations increase, suppressing precipitation at very high concentrations. As this correlation is stronger than the correlation with mean precipitation rate $(r=-0.02)$, this suggests that the change in precipitation rate over the $T+0 \rightarrow+6$ period is not only as result of meteorological covariations.

In contrast, the difference in mean $T-9 \rightarrow-3$ precipitation between the high and low AI populations is strongly correlated to the mean precipitation rate ( $r=-0.5$, not shown). This suggests that the strength of the relationship between AI and $T-9 \rightarrow-3$ precipitation rate is controlled by meteorological factors, as would be expected if wet scavenging was the primary process involved. 


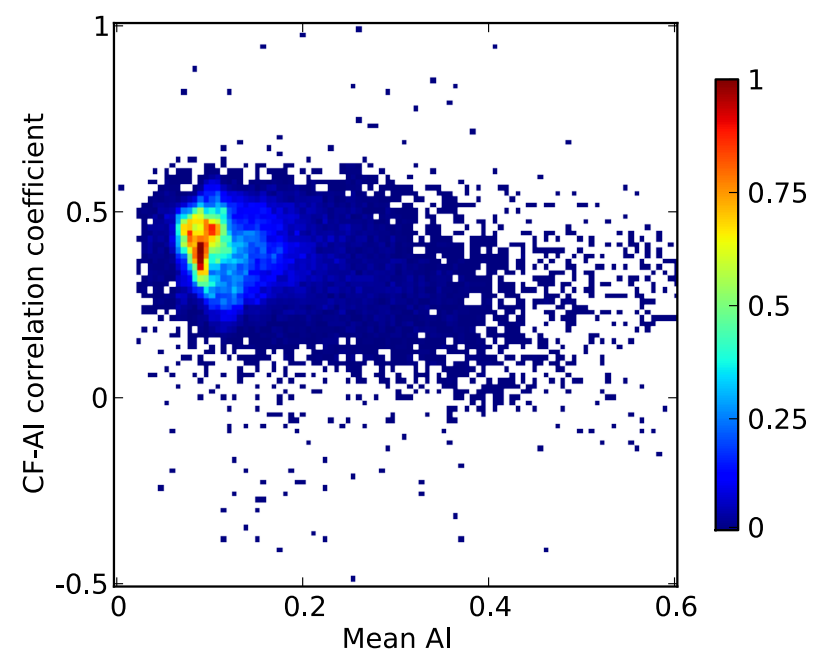

Figure 10. Joint histogram of the AI-CF correlation in the study region as a function of local mean AI, using Terra MODIS data at $1^{\circ}$ by $1^{\circ}$ resolution over the period 2003-2011. The histogram is normalised by the maximum frequency of occurrence.

\subsection{Warm and mixed-phase clouds}

While they depend on CTP, the regimes used in this work do not explicitly separate warm and mixed-phase clouds. However, many hypothesised effects of aerosols on precipitation depend on whether the clouds include ice-phase hydrometeors. We separate out clouds with tops colder than $273 \mathrm{~K}$ using the ISCCP D1 cloud-top temperature retrieval (Rossow and Schiffer, 1999). This is provided on a $3 \mathrm{~h}$ time step, synchronised with the $3 \mathrm{~B} 42$ precipitation retrievals. Unlike the regime, which is determined only at $T+0$, we ensure that the cloud-top temperature is above $273 \mathrm{~K}$ for all the precipitation retrievals at all time offsets in the warm case.

Plotting the precipitation development for each regime, both before and after the AI retrieval (Fig. 2), shows an increase in precipitation after the AI retrieval for the high AI population compared to the low AI population. When repeated using only clouds with tops warmer than $273 \mathrm{~K}$ (Fig. 7), we find a much smaller difference in precipitation development between the high and low AI populations. These warm clouds also have a much smaller precipitation rate compared to the mixed-phase and ice clouds. Clouds with mean cloud-top temperatures warmer than $273 \mathrm{~K}$ contribute about $60 \%$ of the total retrievals we use, but only $10 \%$ of the total retrieved precipitation.

In the warm clouds, the wet scavenging effect (lower rain rate in the high AI population before $T+0$ ) is not so clear (Fig. 7), although it is visible over land in certain regimes. It is likely that this effect is stronger over land due to the larger AI variance. This indicates that the precipitation from these warm clouds is still removing aerosol from the atmosphere and that the wet scavenging effect exists even when the clouds are ice-free. The reduction of the wet scavenging effect when compared to the "all-data" case (no separation between warm and mixed/ice-phase clouds, Fig. 2) is most likely due to the lower overall precipitation rate in the warm clouds.

At times after $T+0$ in the warm clouds (Fig. 7), some regimes do show an increase in retrieved precipitation. This increase is observed in the shallow cumulus and transition regimes. As the TRMM 3B42 product may not be able to accurately retrieve very light rain, the occurrence of this difference in precipitation after $T+0$ in the warm clouds may indicate an increase in cloud liquid water, rather than a precipitation increase. It is also possible that using the $1^{\circ}$ mean cloud-top temperature does not completely screen mixedphase clouds and that this increase is caused by some mixedphase clouds being included in the sample of warm clouds. We should also note that although an aerosol suppression of precipitation has been observed at high AODs (e.g. Lebsock et al., 2008; L'Ecuyer et al., 2009), we do not expect to see it here, as the suppression process mainly impacts light rain, which the TRMM 3B42 product is less sensitive to.

In the mixed/ice-phase case (Fig. 8), the development of the precipitation is very much like the all-data case (Fig. 2), with increased precipitation at times after $T+0$ with increasing AI in many of the regimes, especially over land. This is most likely due to the larger precipitation rate in the clouds with tops colder than $273 \mathrm{~K}$, which generate most (almost $90 \%$ ) of the precipitation observed in the all-data case (Fig. 2).

Restricting the cloud-top temperature restricts the vertical development of the cloud, and prevents the warm clouds growing into higher precipitation rate regimes. The small differences in precipitation rate for the warm clouds (where vertical development is restricted) suggest that the growth into these more highly precipitating regimes is important for generating the difference in precipitation rate between the high and low AI populations. It also suggests that ice processes are likely to be important in an invigoration effect, as we only observe the increase in precipitation for the high AI population compared to the low AI population when clouds tops are allowed to ascend above the freezing level.

\subsection{Instrument effects}

It is possible that the changes in precipitation development we have observed are due to limits in the precipitation retrieval. Whilst the 3B42 retrieval includes data from the TRMM precipitation radar, the majority of retrievals are performed using microwave radiometers and IR geostationary satellites (Huffman et al., 2007). These retrievals make assumptions about the properties of the clouds which may not hold in different aerosol environments, especially if there is a change in cloud properties. The "HQ" product from the TRMM 3B42 version 7 data set provides the non-gaugecorrected merged microwave-only retrieval, without the IR 
precipitation retrieval combined. We use this to investigate the role of the IR precipitation retrieval.

We find that the results are very similar to those including the geostationary IR products (see Supplement). There are a number of small differences; the spike in precipitation rates at $T-2$ (approximately midday) in the anvil cirrus over ocean regime would appear to be due to the IR precipitation retrieval. The difference in precipitation between the high and low AI populations for the marine stratocumulus is also reduced. Finding similar correlations between aerosol and precipitation properties when using the HQ product suggests that the IR retrieval is not the cause of our main results.

We also make use of lightning flash counts from the LIS on board TRMM to provide an independent measure of convective activity, via an increase in flash rate. We treat the LIS flash counts in the same fashion as the 3B42 precipitation data, resulting in a diurnal cycle of flash rates for the high and low AI quartiles in each regime, over both land and ocean (Fig. 9).

There is a large difference between the oceanic and continental flash rates (Fig. 9), with flash rates over land being up to 10 times larger than over ocean for the same regime. This is believed to be due to an increased vigour of convection over land (Zipser, 1994). The peak flash rates in the regimes over land are consistent with the expectation of convective activity within the regimes. The deep convective regime exhibits the largest peak flash rates; the other regimes have similar peak flash rates, with the thick mid-level and anvil cirrus regimes having slightly higher flash rates than the other regimes.

The diurnal cycle in flash rate over land is much stronger than that observed over ocean. We find increases in the flash rate for the high AI populations compared to the low AI population after $T+0$, especially over land. This is similar to the increases in precipitation seen in the high AI population after $T+0$. In the shallow cumulus regime (Fig. 9b), we find a strong increase in the flash rate between $T+1$ and $T+6$, with very little difference at $T+0$. In many of the other regimes, especially over ocean, there are not enough data to draw any significant conclusions about the relationship between AI and the lightning flash rate.

Over both land and ocean, we find little difference between the flash rates of the high and low AI population before $T+0$. This is most likely due to a combination of the lack of data from these regimes and the influence of the diurnal cycle. Low flash rates in the morning ( $T-6$ to $T+0)$ over land are due to the lack of convective activity (Liu and Zipser, 2008). The small influence of lightning on AI likely also plays a role, as unlike precipitation, lightning does not directly remove aerosol from the atmosphere and thus might not be expected to generate a wet scavenging relationship. Combining this with the sparse nature of lightning flashes makes observing any wet-scavenging-like effect very difficult. The significant increase in flash rate for the shallow cumulus regime (Fig. 9b) over land in the high AI population would suggest that the increase in precipitation observed using 3B42 is not due to errors in the precipitation retrieval resulting from the aerosol environment.

\section{Discussion}

Our results appear to show an increase in precipitation with increasing $\mathrm{AI}$ that is not due to the strong AI-CF correlation. There are several possible factors that could be generating the observed results. These can be classified into one of three main types. Firstly, the precipitation retrievals may not be reliable in regions of high aerosol, where the assumptions about the cloud and precipitation properties used in the precipitation retrieval may no longer be valid (e.g. Austin, 1987). Secondly, it is possible that the AI retrieval is not a good proxy for CCN in certain conditions. Sampling issues due to the inability of satellites to retrieve AI in cloudcovered locations may also play a role, especially in precipitating scenes. Finally, type-two meteorological covariations (Gryspeerdt et al., 2014b) resulting in a change of CCN (and AI) along with a change in cloud and precipitation properties could possibly generate the observed relationships without an aerosol effect on precipitation. Each of these possibilities is considered in turn in the following section.

\subsection{Precipitation retrieval errors}

Areal precipitation is a notoriously hard quantity to measure, even using surface instruments. While the random errors in the precipitation retrieval may be large, these are reduced by using a large quantity of data. However, possible systematic errors as a function of aerosol could still be generating our results. The apparent wet scavenging effect at times before $T+0$ provides a possible mechanism for generating systematic errors, especially over land.

Microwave retrievals over land are sensitive to the surface emission properties, which themselves are dependent on soil moisture (Rao et al., 1987; Greenwald et al., 1997). For a given atmospheric profile, a high soil moisture results in a lower brightness temperature and thus, if unaccounted for, higher retrieved precipitation. Due to the wet scavenging of aerosol, the AI retrieval is correlated to precipitation intensity before $T+0$. As such, AI might also be an indicator of soil moisture and thus perhaps an indicator of errors in the precipitation retrieval due to soil moisture.

There are also possible errors in the precipitation retrieval due to the physical basis of the retrievals. Microwave retrievals are known to have difficulty in separating precipitation from cloud water, such that a decrease in precipitation (if it results in an increase in cloud water) may be seen as an increase in precipitation (e.g. Berg et al., 2006). Over land, passive microwave retrievals often have a strong reliance on scattering channels, which have a strong sensitivity to the cloud ice content (Bauer et al., 2005). A possible 
aerosol influence on anvil clouds related to convective systems (Koren et al., 2010) could increase the amount of cloud ice, increasing the retrieved precipitation without changing the surface precipitation.

By comparing the precipitation development results from the 3B42 product (Fig. 2) with the flash rates from the TRMM LIS (Fig. 9) and the reflectivity results from the TRMM PR (see Supplement), we are able to investigate different measurements of precipitation and convective activity, reducing the likelihood that our results are due to precipitation retrieval errors. There is some variation in the results using the different observational tools, although they all show an increase in precipitation/reflectivity/flash rate for the high AI population at times after $T+0$, especially over land. This increases our confidence that our results are due to an increase in precipitation in high-AI environments rather than a change in cloud properties resulting in a larger retrieved precipitation rate. Previous studies have also shown increased transitions into the deep convective regime at high AI, providing further supporting evidence to the aerosol invigoration hypothesis (Gryspeerdt et al., 2014b).

The observation of wet scavenging at times before $T+0$ also provides further evidence that our results are due to a change in precipitation rather than cloud properties. Cloud properties themselves do not influence the AI as strongly as precipitation, and thus they are not expected to generate a relationship before $T+0$ similar to the wet scavenging relationship seen in the precipitation development plots (Fig. 2). The TRMM LIS flash rate provides an example of this, where there is no difference in flash rate between the high and low AI populations before $T+0$ (Fig. 9). As the wet scavenging relationship is only observed when using the precipitation retrieval, this increases our confidence in the ability of the retrieval to determine the precipitation rate. This in turn increases our confidence that the increase in retrieved precipitation for the high AI population compared to the low AI population is due to a change in precipitation rather than cloud properties.

It is important to note the reliance of both the radar and the passive microwave retrievals on assumed droplet size distributions. Aerosols are thought to modify the droplet size distribution, increasing the size of precipitation droplets in convective storms (Rosenfeld and Ulbrich, 2003). In this case, even if the radar and passive microwave results agree on a change in precipitation, we are not able to completely distinguish a change in precipitation rate from an increase in droplet size. However, we might expect an aerosol influence on droplet size to exist both before and after $T+0$. The observation of wet scavenging before $T+0$ suggests that the precipitation retrieval is actually retrieving a change in surface precipitation. Although this is not conclusive, it provides supporting evidence of a change in precipitation rate rather than a change in droplet size.

\subsection{Aerosol retrieval errors}

Systematic errors in the aerosol retrieval may also result in spurious correlations between precipitation and satelliteretrieved aerosol properties (type-one meteorological errors). Previous studies have suggested that the AI may be more closely related to the CCN concentration than AOD (Nakajima et al., 2001). However, the strong correlation with $\mathrm{CF}$ still suggests that other effects, such as humid swelling (e.g. Quaas et al., 2010), are important controlling factors on the AI retrieval.

Whilst AI is not perfectly correlated to $\mathrm{CCN}$, using it to select the highest and the lowest quartiles of CCN should be possible, especially in polluted regions, where there is a large variance in $\mathrm{CCN}$ concentration. In very clean regions, where there is little difference between high and low AI, its ability to separate out high and low CCN may be compromised. In these clean regions, humid swelling or other meteorological effects may be generating most of the difference between high and low retrieved AI. If so, then we may be observing a correlation between precipitation and $\mathrm{CF}$ rather than precipitation and $\mathrm{AI}$ in these clean regions.

Figure 10 shows AI-CF correlation as a function of local mean AI. This provides a measure of how much of the variance in $\mathrm{CF}$ is correlated to $\mathrm{AI}$ variations. If the correlation approaches one, then our method of accounting for the CF influence on AI becomes invalid, as we cannot distinguish fluctuations in AI from fluctuations in CF. As we see here, although there is an increase in the correlation at smaller mean AI, only in a few rare cases is it close to 1 . This suggests that the retrieved AI is not completely correlated to $\mathrm{CF}$, even in very clean regions. Whilst other meteorological variables almost certainly play a role, it does suggest that, even in these clean regions, retrieved $\mathrm{AI}$ is still able to distinguish between high and low $\mathrm{CCN}$ concentrations.

Observations of increased cloud-top height with increasing $\mathrm{CCN}$ over land using in situ aerosol measurements ( $\mathrm{Li}$ et al., 2011) suggest that aerosol retrieval errors are not the primary reason for the observed correlations. Repeated analysis using the AATSR GlobAerosol product (see Supplement) show similar results to those seen when using the MODIS, suggesting that our results are not due to the particular details of the aerosol retrieval.

\subsection{Meteorological covariation}

Even with perfect $\mathrm{CCN}$ and precipitation retrievals, type-two meteorological covariations (Gryspeerdt et al., 2014b) could still be causing the observed effects. When considering precipitation, wet scavenging is also an important consideration and can result in correlations between aerosol and cloud properties (Grandey et al., 2013). We have considered the development of important ECMWF ERA-Interim variables as a function of AI, finding little evidence to support a meteorological effect as the cause of the observed relationships (see 
Supplement). However, there is still the possibility of meteorological influences on our results.

Over both land and ocean, we find an increase in precipitation for times after $T+0$ in the high AI population compared to the low AI population. The regions where we find decreases in precipitation with increasing AI over ocean are regions where biomass burning is a strong contributor to the total aerosol. It would be reasonable to suggest that fires are suppressed when there is high precipitation, so this might generate a negative correlation between aerosol and precipitation. Regime-based analysis may help to reduce these errors by selecting clouds with similar properties at $T+0$ (indicative of similar atmospheric conditions), but the only way to completely determine the influence of these effects is by using a control sample, perhaps demanding the use of a model.

Our results suggest that the change in precipitation with increasing AI is not solely due to meteorological covariation. If high $\mathrm{AI}$ is an indicator of drier atmospheric conditions, we should find a decrease in precipitation for the high AI population at times after $T+0$. Whilst we see a decrease in precipitation with increasing $\mathrm{AI}$ in regions of high mean $\mathrm{AI}$ over ocean, we do not see the same effect over land. This would suggest that a precipitation influence on emission is not the primary cause of our results.

Recent work has suggested that precipitation in the afternoon is more common over drier soils, in contrast to the naïve expectation (Taylor et al., 2012). As high AI is correlated to lower morning precipitation due to the wet scavenging effect, this might indicate a drier surface and thus a higher likelihood of afternoon precipitation. Lower morning precipitation may also indicate a slight shift in the diurnal cycle, picking out situations where the precipitation rate peaks later. These effects are unlikely to be the cause of our results, as previous studies suggest that the temporal auto-correlation in precipitation rates would cause a location with higher precipitation before $T+0$ to be more likely to show a high precipitation after $T+0$ (Lee et al., 2013). This is the opposite to our results.

\section{Conclusions}

In this paper, we have expanded on work studying the temporal development of cloud regimes (Gryspeerdt et al., 2014b), investigating the development of precipitation in these cloud regimes. We separated our data into cloud regimes, and then defined high and low aerosol within these regimes by making use of the MODIS AI. To account for CF influences on the AI retrieval, we ensure that, for each regime, both the high and low AI populations have the same CF distribution at the time of the AI retrieval. Whilst this will remove any aerosol effect on $\mathrm{CF}$ at the time of the AI retrieval, these effects are thought to be small in comparison to meteorological covariations (Quaas et al., 2010).
To investigate the effects of aerosol on precipitation, we study the temporal evolution of the satellite-retrieved precipitation rate. We find an increase in precipitation for the high AI population after $T+0$ in the majority of regimes over land. This increase in precipitation is consistent with the hypothesised aerosol invigoration effect in convective clouds. At times before the aerosol retrieval, we find a higher precipitation rate in the low AI population, consistent with the wet scavenging of aerosols. These effects are smaller over ocean, possibly due to the smaller variance in AI.

Over both ocean and land, there is very little difference in precipitation between the low and high AI populations at the time of the aerosol retrieval. This is in contrast to previous work where a strong correlation between AI and precipitation was observed at the time of the aerosol retrieval (Koren et al., 2012) and is likely due to our accounting for the AI$\mathrm{CF}$ correlation. The small difference in the precipitation rate at $T+0$ emphasises the strong correlation between $\mathrm{CF}$ and precipitation, which would lead to a strong AI-precipitation correlation via the method demonstrated in Gryspeerdt et al. (2014a) if the AI-CF correlation is not accounted for.

The observed increase in precipitation for the $6 \mathrm{~h}$ after the AI retrieval varies by region. In the shallow cumulus regime, an increase in precipitation is found with increasing AI in many regions. However, in regions over ocean with a very high mean AI, a decrease in precipitation is found with increasing AI. This indicates an aerosol suppression of precipitation at very high AI (e.g. Rosenfeld et al., 2008), similar to a decrease in CF previously found at high AOD (Koren et al., 2008).

The change in precipitation development also depends on cloud-top temperature, with the effect being much stronger in clouds with tops colder than $273 \mathrm{~K}$. This may be due to the increased precipitation in these colder clouds, although it might support the hypothesis of ice-phase-driven invigoration of convective clouds.

Due to the possible retrieval errors in the TRMM 3B42 precipitation retrieval, other measures of convective activity are also investigated. An increase in TRMM LIS lightning flash rate is observed at times after $T+0$ in the shallow cumulus regime for the high AI population compared to the low AI one. This suggests that the observed increase in precipitation with increasing AI is not primarily due to precipitation retrieval errors. However, we cannot completely rule out the possibility that changes in the precipitation droplet size distribution are responsible for our results.

Whilst it is possible that our observed results are due to either systematic biases in the aerosol or precipitation retrievals, or that they are the product of remaining meteorological covariation, we have accounted for the largest known meteorological covariations in this study. This work provides a new picture of how precipitation might vary in response to aerosol perturbations. Accounting for some of the larger known errors reduces the apparent influence of aerosols on precipitation, but the results presented in this study are 
consistent with an invigoration of precipitation from convective clouds in the presence of higher aerosol concentrations.

\section{The Supplement related to this article is available online at doi:10.5194/acp-14-9677-2014-supplement.}

Acknowledgements. The MODIS data are from the NASA Goddard Space Flight Center and the ISCCP data are from the NASA Langley Atmospheric Research Center. The TRMM data were acquired as part of the activities of NASA's Science Mission Directorate, and are archived and distributed by the Goddard Earth Sciences (GES) Data and Information Services Center (DISC). The LIS data were obtained using the NASA Reverb/ECHO system. The MIDAS data were obtained from the British Atmospheric Data Centre (BADC). The authors gratefully acknowledge the NOAA Air Resources Laboratory (ARL) for the provision of the HYSPLIT transport and dispersion model used in this publication. This work was supported by a UK Natural Environment Research Council (NERC) DPhil studentship and funding from the European Research Council under the European Union's Seventh Framework Programme (FP7/2007-2013)/ERC grant agreement no. FP7-280025.

Edited by: H. Su

\section{References}

Adler, R. F., Huffman, G. J., Bolvin, D. T., Curtis, S., and Nelkin, E. J.: Tropical Rainfall Distributions Determined Using TRMM Combined with Other Satellite and Rain Gauge Information, J. App. Met., 39, 2007-2023, doi:10.1175/15200450(2001)040<2007:TRDDUT>2.0.CO;2, 2000.

Albrecht, B.: Aerosols, Cloud Microphysics, and Fractional Cloudiness, Science, 245, 1227-1230, doi:10.1126/science.245.4923.1227, 1989.

Allen, M. and Ingram, W.: Constraints on future changes in climate and the hydrologic cycle, Nature, 419, 224-232, doi:10.1038/nature01092, 2002.

Andreae, M.: Correlation between cloud condensation nuclei concentration and aerosol optical thickness in remote and polluted regions, Atmos. Chem. Phys., 9, 543-556, doi:10.5194/acp-9543-2009, 2009.

Austin, P. M.: Relation between Measured Radar Reflectivity and Surface Rainfall, 115, 1053-1070, doi:10.1175/15200493(1987)115<1053:RBMRRA>2.0.CO;2, 1987.

Bauer, P., Moreau, E., and di Michele, S.: Hydrometeor Retrieval Accuracy Using Microwave Window and Sounding Channel Observations., J. App. Met., 44, 1016-1032, doi:10.1175/JAM2257.1, 2005.

Berg, W., L'Ecuyer, T., and Kummerow, C.: Rainfall Climate Regimes: The Relationship of Regional TRMM Rainfall Biases to the Environment, J. App. Met. Clim., 45, 434-454, doi:10.1175/JAM2331.1, 2006.
Boucher, O. and Quaas, J.: Water vapour affects both rain and aerosol optical depth, Nat. Geosci., 6, 4-5, doi:10.1038/ngeo1692, 2012.

Christian, H. J.: Global frequency and distribution of lightning as observed from space by the Optical Transient Detector, J. Geophys. Res., 108, D14005, doi:10.1029/2002JD002347, 2003.

Draxler, R. and Hess, G.: An overview of the HYSPLIT_4 modeling system of trajectories, dispersion and deposition, Aust. Meteor. Mag., 47, 295-308, 1998.

Engström, A. and Magnusson, L.: Estimating trajectory uncertainties due to flow dependent errors in the atmospheric analysis, Atmos. Chem. Phys., 9, 8857-8867, doi:10.5194/acp-9-8857-2009, 2009.

Grandey, B. S., Stier, P., and Wagner, T. M.: Investigating relationships between aerosol optical depth and cloud fraction using satellite, aerosol reanalysis and general circulation model data, Atmos. Chem. Phys., 13, 3177-3184, doi:10.5194/acp-13-31772013, 2013.

Greenwald, T. J., Combs, C. L., Jones, A. S., Randel, D. L., and Vonder Haar, T. H.: Further Developments in Estimating Cloud Liquid Water over Land Using Microwave and Infrared Satellite Measurements., J. App. Met., 36, 389-405, doi:10.1175/15200450(1997)036<0389:FDIECL>2.0.CO;2, 1997.

Gryspeerdt, E. and Stier, P.: Regime-based analysis of aerosolcloud interactions, Geophys. Rev. Lett., 39, L21802, doi:10.1029/2012GL053221, 2012.

Gryspeerdt, E., Stier, P., and Grandey, B.: Cloud fraction mediates the aerosol optical depth - cloud top height relationship, Geophys. Rev. Lett., 41, doi:10.1002/2014GL059524, 2014a.

Gryspeerdt, E., Stier, P., and Partridge, D. G.: Satellite observations of cloud regime development: the role of aerosol processes, Atmos. Chem. Phys., 14, 1141-1158, doi:10.5194/acp-14-11412014, 2014b.

Huang, J., Zhang, C., and Prospero, J.: African aerosol and largescale precipitation variability over West Africa, Env. Res. Lett., 4, 015006, doi:10.1088/1748-9326/4/1/015006, 2009.

Huffman, G. J., Bolvin, D. T., Nelkin, E. J., Wolff, D. B., Adler, R. F., Gu, G., Hong, Y., Bowman, K. P., and Stocker, E. F.: The TRMM Multisatellite Precipitation Analysis (TMPA): Quasi-Global, Multiyear, Combined-Sensor Precipitation Estimates at Fine Scales, J. Hydrometeorology, 8, 38-55, doi:10.1175/JHM560.1, 2007.

Huffman, G. J., Adler, R. F., Bolvin, D. T., and Gu, G.: Improving the global precipitation record: GPCP Version 2.1, Geophys. Res. Lett., 36, L17808, doi:10.1029/2009GL040000, 2009.

Kaufman, Y., Koren, I., Remer, L., Rosenfeld, D., and Rudich, Y.: The effect of smoke, dust, and pollution aerosol on shallow cloud development over the Atlantic Ocean, P Natl. A. Sci., 102, 11207, doi:10.1073/pnas.0505191102, 2005.

Khain, A.: Notes on state-of-the-art investigations of aerosol effects on precipitation: a critical review, Env. Res. Lett., 4, 015004, doi:10.1088/1748-9326/4/1/015004, 2009.

Koren, I., Martins, J., Remer, L. A., and Afargan, H.: Smoke Invigoration Versus Inhibition of Clouds over the Amazon, Science, 321, 946-949, doi:10.1126/science.1159185, 2008.

Koren, I., Remer, L., Altaratz, O., Martins, J., and Davidi, A.: Aerosol-induced changes of convective cloud anvils produce strong climate warming, Atmos. Chem. Phys., 10, 5001-5010, doi:10.5194/acp-10-5001-2010, 2010. 
Koren, I., Altaratz, O., Remer, L. A., Feingold, G., Martins, J. V., and Heiblum, R. H.: Aerosol-induced intensification of rain from the tropics to the mid-latitudes, Nature Geosci., 5, 118, doi:10.1038/ngeo1364, 2012.

Koren, I., Altaratz, O., Remer, L. A., Feingold, G., Martins, J. V., and Heiblum, R.: Reply to 'Water vapour affects both rain and aerosol optical depth', Nat. Geosci., 6, 5, doi:10.1038/ngeo1693, 2013.

Kummerow, C., Barnes, W., Kozu, T., Shiue, J., and Simpson, J.: The Tropical Rainfall Measuring Mission (TRMM) Sensor Package, J. Atmos. Ocean Tech., 15, 809-817, doi:10.1175/15200426(1998)015<0809:TTRMMT>2.0.CO;2, 1998.

Lebo, Z. and Seinfeld, J.: Theoretical basis for convective invigoration due to increased aerosol concentration, Atmos. Chem. Phys., 11, 5407-5429, doi:10.5194/acp-11-5407-2011, 2011.

Lebsock, M., Stephens, G., and Kummerow, C.: Multisensor satellite observations of aerosol effects on warm clouds, J. Geophys. Res., 113, D15205, doi:10.1029/2008JD009876, 2008.

L'Ecuyer, T., Berg, W., Haynes, J., Lebsock, M., and Takemura, T.: Global observations of aerosol impacts on precipitation occurrence in warm maritime clouds, J. Geophys. Res., 114, D09211, doi:10.1029/2008JD011273, 2009.

Lee, D., Oreopoulos, L., Huffman, G. J., Rossow, W. B., and Kang, I.-S.: The Precipitation Characteristics of ISCCP Tropical Weather States, J. Climate, 26, 772-788, doi:10.1175/JCLI-D11-00718.1, 2013.

Levin, Z. and Cotton, W.: Aerosol Pollution Impact on Precipitation, Springer Science+Business Media, New York, NY, USA and Heidelberg, Germany, 2009.

Li, Z., Niu, F., Fan, J., Liu, Y., Rosenfeld, D., and Ding, Y.: Longterm impacts of aerosols on the vertical development of clouds and precipitation, Nat. Geosci., 4, 888, doi:10.1038/ngeo1313, 2011.

Lin, J., Matsui, T., Pielke, R., and Kummerow, C.: Effects of biomass-burning-derived aerosols on precipitation and clouds in the Amazon Basin: A satellite-based empirical study, J. Geophys. Res., 111, D19204, doi:10.1029/2005JD006884, 2006.

Liu, C. and Zipser, E. J.: Diurnal cycles of precipitation, clouds, and lightning in the tropics from 9 years of TRMM observations, Geophys. Res. Lett., 35, L04819, doi:10.1029/2007GL032437, 2008.

Nakajima, T., Higurashi, A., Kawamoto, K., and Penner, J.: A possible correlation between satellite-derived cloud and aerosol microphysical parameters, Geophys. Res. Lett., 28, 1171-1174, doi:10.1029/2000GL012186, 2001.

Niu, F. and Li, Z.: Systematic variations of cloud top temperature and precipitation rate with aerosols over the global tropics, Atmos. Chem. Phys., 12, 8491-8498, doi:10.5194/acp-12-84912012, 2012.

Platnick, S., King, M., Ackerman, S., Menzel, W., Baum, B., Riedi, J., and Frey, R.: The MODIS cloud products: algorithms and examples from Terra, IEEE T. GeoSci. Remote, 41, 459, doi:10.1109/TGRS.2002.808301, 2003.

Quaas, J., Stevens, B., Stier, P., and Lohmann, U.: Interpreting the cloud cover - aerosol optical depth relationship found in satellite data using a general circulation model, Atmos. Chem. Phys., 10, 6129-6135, doi:10.5194/acp-10-6129-2010, 2010.

Rao, K. S., Chandra, G., and Rao, P. V. N.: The relationship between brightness temperature and soil moisture Selection of frequency range for microwave remote sensing, Int. J. Remote Sens., 8, 1531-1545, doi:10.1080/01431168708954795, 1987.

Remer, L., Kaufman, Y., Tanré, D., Matto, S., Chu, D., Martins, J., Li, R.-R., Ichoku, C., Levy, R., Kleidman, R., Eck, T., Vermote, E., and Holben, B.: The MODIS aerosol algorithm, products, and validation, J. Atmos. Sci., 62, 947-973, doi:10.1175/JAS3385.1, 2005.

Rosenfeld, D.: TRMM Observed First Direct Evidence of Smoke from Forest Fires Inhibiting Rainfall, Geophys. Res. Lett., 26, 3105-3108, doi:10.1029/1999GL006066, 1999.

Rosenfeld, D. and Ulbrich, C. W.: Cloud microphysical properties, processes, and rainfall estimation opportunities., in: Radar and Atmospheric Science: A Collection of Essays in Honor of David Atlas, Meteor. Monogr., edited by Wakimoto, R. M. and Srivastava, R., Vol. 52, 10, 237-258, AMS, 2003.

Rosenfeld, D., Lohmann, U., Raga, G., O’Dowd, C., Kulmala, M., Fuzzi, S., Reissell, A., and Andreae, M.: Flood or Drought: How Do Aerosols Affect Precipitation?, Science, 321, 1309-1313, doi:10.1126/science.1160606, 2008.

Rossow, W. and Schiffer, R.: Advances in Understanding Clouds from ISCCP., B. Am. Meteorol. Soc., 80, 2261-2287, doi:10.1175/1520-0477(1999)080<2261:AIUCFI>2.0.CO;2, 1999.

Sorooshian, A., Feingold, G., Lebsock, M., Jiang, H., and Stephens, G.: On the precipitation susceptibility of clouds to aerosol perturbations, Geophys. Res. Lett., 36, L13803, doi:10.1029/2009GL038993, 2009.

Stevens, B. and Feingold, G.: Untangling aerosol effects on clouds and precipitation in a buffered system, Nature, 461, 607-613, doi:10.1038/nature08281, 2009.

Taylor, C. M., de Jeu, R. A. M., Guichard, F., Harris, P. P., and Dorigo, W. A.: Afternoon rain more likely over drier soils., Nature, 489, 423-426, doi:10.1038/nature11377, 2012.

Textor, C., Schulz, M., Guibert, S., Kinne, S., Balkanski, Y., Bauer, S., Berntsen, T., Berglen, T., Boucher, O., Chin, M., Dentener, F., Diehl, T., Easter, R., Feichter, H., Fillmore, D., Ghan, S., Ginoux, P., Gong, S., Grini, A., Hendricks, J., Horowitz, L., Huang, P., Isaksen, I., Iversen, I., Kloster, S., Koch, D., Kirkevåg, A., Kristjansson, J., Krol, M., Lauer, A., Lamarque, J., Liu, X., Montanaro, V., Myhre, G., Penner, J., Pitari, G., Reddy, S., Seland, $\emptyset$., Stier, P., Takemura, T., and Tie, X.: Analysis and quantification of the diversities of aerosol life cycles within AeroCom, Atmos. Chem. Phys., 6, 1777-1813, doi:10.5194/acp-6-1777-2006, 2006.

Twohy, C., Coakley, J., and Tahnk, W.: Effect of changes in relative humidity on aerosol scattering near clouds, J. Geophys. Res., 114, D05205, doi:10.1029/2008JD010991, 2009.

Twomey, S.: The Influence of Pollution on the Shortwave Albedo of Clouds., J. Atmos. Sci., 34, 1149-1152, doi:10.1175/15200469(1977)034<1149:TIOPOT>2.0.CO;2, 1977.

Weigum, N. M., Stier, P., Schwarz, J. P., Fahey, D. W., and Spackman, J. R.: Scales of variability of black carbon plumes over the Pacific Ocean, 39, L15804, doi:10.1029/2012GL052127, 2012.

Wen, G., Marshak, A., Cahalan, R., Remer, L., and Kleidman, R.: 3-D aerosol-cloud radiative interaction observed in collocated MODIS and ASTER images of cumulus cloud fields, J. Geophys. Res., 112, D13204, doi:10.1029/2006JD008267, 2007.

Williams, E., Rosenfeld, D., Madden, N., Gerlach, J., Gears, N., Atkinson, L., Dunnemann, N., Frostrom, G., Antonio, M., Bi- 
azon, B., Camargo, R., Franca, H., Gomes, A., Lima, M., Machado, R., Manhaes, S., Nachtigall, L., Piva, H., Quintiliano, W., Machado, L., Artaxo, P., Roberts, G., Renno, N., Blakeslee, R., Bailey, J., Boccippio, D., Betts, A., Wolff, D., Roy, B., Halverson, J., Rickenbach, T., Fuentes, J., and Avelino, E.: Contrasting convective regimes over the Amazon: Implications for cloud electrification, J. Geophys. Res., 107, 8082, doi:10.1029/2001JD000380, 2002.

Williams, K. and Webb, M.: A quantitative performance assessment of cloud regimes in climate models, Climate Dyn., 33, 141-157, doi:10.1007/s00382-008-0443-1, 2009.
Yuan, T., Remer, L. A., Pickering, K. E., and Yu, H.: Observational evidence of aerosol enhancement of lightning activity and convective invigoration, Geophys. Res. Lett, 38, L04701, doi:10.1029/2010GL046052, 2011.

Zhang, J., Reid, J., and Holben, B.: An analysis of potential cloud artifacts in MODIS over ocean aerosol optical thickness products, Geophys. Res. Lett., 32, L15803, doi:10.1029/2005GL023254, 2005.

Zipser, E. J.: Deep Cumulonimbus Cloud Systems in the Tropics with and without Lightning, M. Weather Rev., 122, 1837-1851, doi:10.1175/1520-0493(1994)122<1837:DCCSIT>2.0.CO;2, 1994. 